\title{
OBTENÇÃO E CARACTERIZAÇÃO DE FARINHAS DE SOJA DE VARIEDADES GENETICAMENTE MELHORADAS PARA ALIMENTAÇÃO HUMANA
}

\author{
A. A. RIGO ${ }^{1}$, A. M. DAHMER ${ }^{1}$, C. STEFFENS ${ }^{1}$, J. STEFFENS ${ }^{1}$, M. C. CARRÃO- \\ PANIZZI $^{2}$, R. S. LEITE ${ }^{2}$, J. M. G. MANDARINO ${ }^{2}$, A. M. DE CEZARO ${ }^{1}$ \\ ${ }^{1}$ Universidade Regional Integrada do Alto Uruguai e das Missões, Faculdade de Engenharia \\ de Alimentos \\ 2 Empresa Brasileira de Pesquisa Agropecuária (Embrapa) \\ E-mail para contato: aline.andressa@hotmail.com
}

\begin{abstract}
RESUMO - A soja (Glycine max (L.) Merrill) é uma das culturas de maior importância econômica no mundo. Em vista disso, as cultivares convencionais de soja geralmente são direcionadas para as indústrias de extração de óleo e o subproduto destas indústrias destinadas a alimentação animal. Contudo algumas cultivares de soja geneticamente melhoradas podem apresentar características que as tornam adequadas para diferentes utilizações, inclusive na alimentação humana. Assim, este trabalho teve como objetivo obter e caracterizar farinhas de soja provenientes de três variedades, uma convencional (Vmax), e duas para alimentação humana (BR 257 e BRS 267), quanto a sua composição físicoquímica e solubilidade proteica. As farinhas foram caracterizadas em relação a umidade, proteínas, lipídeos, cinzas, e índices de solubilidade proteica. Nas cultivares Vmax e BRS 267 foi efetuado o processo de branqueamento nos grãos com e sem casca. Para obtenção das farinhas os grãos sem branqueamento (Vmax, BRS 257 e BRS 267) e branqueados (Vmax e BRS 267), ambos com e sem casca, passaram pelo processo de torra, moagem e peneiramento. O processo de torra a $150^{\circ} \mathrm{C}$ por 30 minutos fez com que a solubilidade proteica atingisse valores abaixo de $10 \%$, devido a severidade do tratamento. A farinha da variedade BRS 267 demostrou um maior conteúdo proteico, podendo melhorar o valor nutricional de alimentos a base de soja. Já a farinha obtida da cultivar Vmax foi a que mostrou o maior conteúdo lipídico, podendo ser utilizada nas indústrias de extração de óleo, para o fabrico de uma infinidade de produtos. Na farinha da cultivar BRS 257, foi observada uma composição química com valores intermediários as demais cultivares, mas com a vantagem de não necessitar de processamento térmico para a inativação das enzimas lipoxigenases (LOXs).
\end{abstract}

\section{INTRODUÇÃO}

A soja é uma das fontes proteicas mais utilizadas no mundo. No entanto suas características organolépticas não são adequadas para a produção de alimentos (Chen e Buss, 2004). Neste sentido, o desenvolvimento de cultivares de soja mais adequada para o consumo humano é importante para atender à demanda de mercado por cultivares com características qualitativas específicas (Carrão-Panizzi et al., 2012).

A partir desta necessidade de produtos de soja com sabor mais agradável, e com alto valor nutritivo a Empresa Brasileira de Pesquisa Agropecuária, Centro Nacional de Pesquisa 
da Soja (Embrapa Soja) desenvolveu, por meio do seu programa de melhoramento genético, algumas cultivares de soja cujas características especiais as tornam adequadas para diferentes utilizações (Carrão-Panizzi et al., 2009).

A cultivar de soja BRS 267 apresenta grãos graúdos e se constitui como matéria-prima adequada para ser consumida como hortaliça (Edamame) ou para processamento de tofu (Carrão-Panizzi et al., 2009). Essa cultivar apresenta elevado teor protéico, maior teor do ácido oléico, teor de agliconas, de açúcares, dos aminoácidos ácido glutâmico e alanina, características que podem resultar em sabor mais agradável em alimentos de soja, melhorando também o seu valor nutricional (Silva, 2009). Já a cultivar BRS 257, não apresenta as enzimas lipoxigenases que são responsáveis pelo desenvolvimento dos sabores de ranço ou de feijão cru (beany flavor), possui rendimento elevado e é mais indicada para a processamento de farinha e extrato hidrossolúvel de soja (Carrão-Panizzi et al., 2009).

A soja é um grão muito versátil que dá origem a produtos e subprodutos muito usados pela agroindústria, indústria química e de alimentos (Ciabotti et al., 2007). Entre os diversos produtos que podem ser fabricados, a farinha de soja é amplamente utilizada na indústria como um ingrediente para aumentar o conteúdo de proteínas de muitos alimentos, tais como em panificação (He e Chen, 2013). Além de suas vantagens nutricionais, a farinha de soja proporciona melhorias de propriedades funcionais como viscosidade, absorção de água, absorção de gordura, propriedades emulsificantes, espumantes, gelificação, entre outras (Nascimento, 2008). Dessa maneira, a farinha de soja, torna se uma alternativa para otimizar a elaboração de produtos derivados de soja para o consumo humano.

Em vista disso, o trabalho teve como objetivo obter e caracterizar farinhas de soja provenientes de três variedades, uma convencional (Vmax), e duas para alimentação humana (BRS 257 e 267), quanto a sua composição físico-química e solubilidade proteica.

\section{MATERIAL E MÉTODOS}

Os grãos de soja das cultivares Vmax, BRS 257 e BRS 267 foram cedidos pela Embrapa, provenientes da safra 2012/2013, cultivados na região de Passo Fundo - RS, Brasil (Latitude $\left.28^{\circ} 15^{\prime} 40^{\prime \prime}\right)$. Estas cultivares foram avaliadas com casca (CC) e sem casa (SC), sendo o descasque dos grãos realizados por um descascador de soja $\left(\right.$ Maqso $\left.^{\circledR}\right)$.

As variedades BRS 267 e Vmax possuem as enzimas lipoxigenases (LOX), por essa razão, essas cultivares passaram pelo processo de branqueamento por imersão dos grãos em banho de água à $98^{\circ} \mathrm{C}$ por 5 minutos, conforme descrito por Ciabotti et al. (2006). Em seguida os grãos foram secos a uma temperatura de $40^{\circ} \mathrm{C}$, como o recomendado por França Neto et al. (2007), em estufa com circulação de ar (Marconi $\left.{ }^{\circledR}\right)$, por 24 horas até massa constante. Como a variedade BRS 257 é uma linhagem de soja com ausência das lipoxigenases (Carrão-Panizzi, 2009), esta não sofreu o processo de branqueamento.

Dos tratamentos descritos acima foram obtidos amostras da cultivar Vmax e BRS 267 CC e SC sendo elas branqueadas (B) e sem branqueamento (SB), enquanto que da cultivar BRS 257 foi somente avaliado CC e SC ambas SB, obtendo assim 10 diferentes amostras de farinhas. 
Para obtenção da farinha de soja as 10 amostras definidas anteriormente foram submetidas ao processo de torra a $150^{\circ} \mathrm{C}$ por $30 \mathrm{~min}$, conforme a metodologia de Dantas et al. (2010). Após a torra, os grãos foram moídos em moedor Cuisinart (modelo DCG-20BKN) e peneirados em peneiras de 40 mesh, conforme a metodologia de Silva et al. (2010).

O teor de umidade foi determinado pelo método gravimétrico em estufa (Nova Ética ${ }^{\circledR}$ ) a $105^{\circ} \mathrm{C}$ por aproximadamente $4 \mathrm{~h}$. Os valores de umidade dos grãos foram padronizados em 2,52\% (extrato seco de 97,48) para as análises de proteínas, lipídeos e cinzas, sendo que as proteínas foram determinadas pelo método de Kjeldahl, os lipídeos foram obtidos pelo método de Soxhlet e cinzas foram obtidas em mufla (Quimis ${ }^{\circledR}$ ) a $550^{\circ} \mathrm{C}$ por $6 \mathrm{~h}$. Todas as análises foram realizadas de acordo com a metodologia da AOAC (2007) e os resultados expressos em $\mathrm{g} / 100 \mathrm{~g}$ em base seca.

O índice de solubilidade de nitrogênio (ISN) foi determinado segundo o método descrito na AOCS (1980), onde $5 \mathrm{~g}$ de amostra foram diluídos em $200 \mathrm{~mL}$ de água destilada, agitados em banho incubador (Nova Ética ${ }^{\circledR}$ ) a $120 \mathrm{rpm}$ a $30^{\circ} \mathrm{C}$ por $2 \mathrm{~h}$. Após esse tempo o sobrenadante foi centrifugado (centrífuga $\mathrm{MPW}^{\circledR}$ modelo $351 \mathrm{R}$ ), por $10 \mathrm{~min}$ a $1500 \mathrm{rpm}$, o filtrado obtido foi utilizado para a determinação de proteína bruta pelo método oficial da AOAC (2007). O resultado foi expresso em percentagem (\%). Já o índice de dispersibilidade proteica (IDP) foi determinado segundo o método descrito na AOCS (1980), onde $10 \mathrm{~g}$ de amostra foram diluídos em $250 \mathrm{~mL}$ de água destilada, agitado em homogeneizador (modelo T18 Basic Ultra-Turrax) a $8500 \mathrm{rpm}$ por $10 \mathrm{~min}$. O sobrenadante foi centrifugado (centrífuga $\mathrm{MPW}^{\circledR}$ modelo 351R), por $10 \mathrm{~min}$ a $2700 \mathrm{rpm}$, o filtrado obtido foi utilizado para a determinação de proteína bruta pelo método oficial da AOAC (2007). O resultado foi expresso em percentagem $(\%)$.

Todas as análises foram realizadas em triplicatas e seus respectivos resultados foram submetidos análise de variância (ANOVA), e as médias comparadas pelo teste de Tukey, a nível de 95\% de confiança, utilizando o software Statistica 8.0.

\section{RESULTADOS E DISCUSSÃO}

Os teores de proteína bruta, lipídeos, cinzas, índice de dispersibilidade proteica (IDP) e o índice de solubilidade do nitrogênio (ISN) das farinhas de soja das três cultivares, com e sem branqueamento (B e SB), estão apresentados na Tabela 1.

A farinha da BRS 267 B (SC) apresentou o maior teor proteico com 47,04 g/100g, e a farinha de menor conteúdo proteico foi a Vmax SB (CC) com 37,21 g/100g. No trabalho de Santos et al. (2012), a farinha de kinako da cultivar BRS 257 apresentou 45,65 g/100g, valor superior ao deste trabalho que foi de $38,94 \mathrm{~g} / 100 \mathrm{~g}$, nos grãos CC. Nas cultivares SC foram observados os maiores teores de proteínas diferindo significativamente dos grãos $\mathrm{CC}$, com exceção apenas da BRS 257 SB que não apresentou diferença significativa. Quando a casca é retirada a concentração proteica pode ser aumentada, pois a maior parte das proteínas está armazenada nos cotilédones, sob a forma de corpos protéicos que são responsáveis por 60$70 \%$ do total de proteína da semente (Saidu, 2005; Silva, 2007). 
Tabela 1 - Teores de proteína bruta, lipídeos, cinzas, índice de dipersibilidade proteica (IDP) e índice de solubilidade de nitrogênio (ISN), das farinhas de soja provenientes de grãos branqueados (B) e sem branqueamento (SB) das cultivares BRS 267, BRS 257 e Vmax.

\begin{tabular}{ccccccc}
\hline Análises & & & \multicolumn{5}{c}{ Farinhas } \\
& & BRS 267 SB & BRS 267 B & Vmax SB & Vmax B & BRS 257 SB \\
\hline Proteína & CC & $41,67( \pm 0,38)^{\mathrm{aB}}$ & $41,93( \pm 0,11)^{\mathrm{aB}}$ & $37,21( \pm 0,15)^{\mathrm{cB}}$ & $37,37( \pm 0,29)^{\mathrm{cB}}$ & $38,94( \pm 0,08)^{\mathrm{bB}}$ \\
$(\mathrm{g} / 100 \mathrm{~g})$ & $\mathrm{SC}$ & $44,02( \pm 0,11)^{\mathrm{bA}}$ & $47,04( \pm 0,54)^{\mathrm{aA}}$ & $38,90( \pm 0,23)^{\mathrm{dA}}$ & $41,20( \pm 0,39)^{\mathrm{cA}}$ & $41,15( \pm 0,22)^{\mathrm{cA}}$ \\
Cinzas & $\mathrm{CC}$ & $5,46( \pm 0,69)^{\mathrm{aA}}$ & $5,15( \pm 0,23)^{\mathrm{aA}}$ & $4,65( \pm 0,43)^{\mathrm{aA}}$ & $5,06( \pm 0,50)^{\mathrm{aA}}$ & $5,26( \pm 0,40)^{\mathrm{aA}}$ \\
$(\mathrm{g} / 100 \mathrm{~g})$ & $\mathrm{SC}$ & $5,54( \pm 0,26)^{\mathrm{aA}}$ & $5,32( \pm 0,16)^{\mathrm{abA}}$ & $4,91( \pm 0,12)^{\mathrm{abA}}$ & $4,16( \pm 0,73)^{\mathrm{bA}}$ & $5,50( \pm 0,53)^{\mathrm{aA}}$ \\
Lipídeos & $\mathrm{CC}$ & $19,89( \pm 0,89)^{\mathrm{dA}}$ & $21,70( \pm 2,81)^{\mathrm{cdA}}$ & $27,64( \pm 0,44)^{\mathrm{aB}}$ & $27,61( \pm 1,43)^{\mathrm{abA}}$ & $25,45( \pm 0,47)^{\mathrm{bcA}}$ \\
$(\mathrm{g} / 100 \mathrm{~g})$ & $\mathrm{SC}$ & $20,74( \pm 0,86)^{\mathrm{bA}}$ & $22,09( \pm 3,13)^{\mathrm{bA}}$ & $29,50( \pm 0,24)^{\mathrm{aA}}$ & $29,25( \pm 3,00)^{\mathrm{aA}}$ & $25,94( \pm 0,80)^{\mathrm{abA}}$ \\
& $\mathrm{CC}$ & $7,51( \pm 0,05)^{\mathrm{bA}}$ & $9,27( \pm 1,26)^{\mathrm{abA}}$ & $7,99( \pm 1,37)^{\mathrm{bA}}$ & $7,95( \pm 0,70)^{\mathrm{bA}}$ & $10,68( \pm 0,70)^{\mathrm{aA}}$ \\
IDP $(\%)$ & $\mathrm{SC}$ & $6,70( \pm 1,16)^{\mathrm{bA}}$ & $6,90( \pm 0,60)^{\mathrm{bB}}$ & $6,08( \pm 0,63)^{\mathrm{bA}}$ & $6,46( \pm 0,05)^{\mathrm{bB}}$ & $9,35( \pm 0,66)^{\mathrm{aA}}$ \\
& $\mathrm{CC}$ & $8,00( \pm 0,98)^{\mathrm{bA}}$ & $10,25( \pm 1,70)^{\mathrm{aA}}$ & $7,66( \pm 0,01)^{\mathrm{bA}}$ & $9,53( \pm 0,06)^{\mathrm{aA}}$ & $7,93( \pm 1,05)^{\mathrm{bA}}$ \\
ISN $(\%)$ & $\mathrm{SC}$ & $8,57( \pm 0,91)^{\mathrm{aA}}$ & $7,51( \pm 1,50)^{\mathrm{abA}}$ & $5,47( \pm 0,02)^{\mathrm{bB}}$ & $7,47( \pm 0,92)^{\mathrm{abB}}$ & $8,06( \pm 0,99)^{\mathrm{abA}}$ \\
\hline
\end{tabular}

Média (três repetições) \pm Desvio Padrão seguidas de letras iguais minúsculas/maiúsculas na linha/coluna (análise) indicam não haver diferença significativa a nível de $5 \%$ (teste de Tukey).

Onde: $\mathrm{B}=$ grão branqueado; $\mathrm{SB}$ = grão sem branqueamento; $\mathrm{CC}=$ com casca; $\mathrm{SC}=$ sem casca.

Nos teores de cinzas das farinhas não houveram diferenças significativas entre as culivares e nem mesmo entre grãos CC e SC da mesma cultivar. Apresentando um teor médio de $5,11 \mathrm{~g} / 100 \mathrm{~g}$ nas farinhas com casca. As variações nos valores de cinzas nas farinhas SC podem ser explicadas pelo descasque mecânico, permitindo a presença de alguns resíduos de casca que podem interferir na composição do teor de cinzas.

Os resultados quanto ao teor de cinzas em farinhas de soja na literatura apontam diferenças que podem estar relacionadas com as características próprias de cada cultivar de soja e das condições edafoclimáticas. Segundo Santos et al. (2012), para farinha de soja da BRS 257, encontraram um teor de cinzas de 6,89 g/100g, já Silva et al. (2012), avaliando a composição centesimal da farinha de soja integral da variedade BRS 232, constataram um teor de 4,81 g/100g, semelhante aos encontrados neste trabalho.

O maior teor de lipídeos foi observado nas farinhas provenientes de grãos SC, pois como observado por Guarienti et al. (2012) a quantidade de óleo na porção casca é reduzida. A farinha da cultivar Vmax SB (SC) apresentou o maior valor com 29,5 g/100g e a BRS 267 SB (CC) o menor teor com 19,89 g/100g. Essa característica do teor de óleo serve como indicador para o uso tecnológico, com elevado teor a cultivar Vmax pode ser usada para aumentar o conteúdo lipídico no processamento de alimentos ou nas indústrias de extração de óleo. Diferentemente da BRS 267 que apresenta um baixo teor de lipídeos, a qual em contra partida, apresenta um elevado teor de proteínas, podendo ser recomendada para a adição em alimentos para melhor valor nutricional.

Com relação ao IDP, apenas as farinhas da cultivar BRS 257 SB apresentaram um valor superior as demais com 10,68\% e 9,35\%, com e sem casca, respectivamente. Entretanto considerando grãos $\mathrm{CC}$ e SC, percebe-se que as farinhas provenientes de grãos SB foram semelhantes entre cultivares, com diferença somente para o ISN da cultivar Vmax SC. Já os ISN nas farinhas de grãos CC não houveram diferenças significativas, demostrando uma 
média de $8,67 \%$. Na comparação de culivares nota-se que entre grãos SB SC apenas a BRS $267 \mathrm{SB}(8,57 \%)$ e a Vmax $(5,47 \%)$ exibiram diferenças $(\mathrm{p}<0,05)$. Vale salientar que grãos de soja sem tratamento térmico, apresentam, aproximadamente, uma solubilidade proteica acima de 70\% (SILVA et al., 2008).

No trabalho de Arndt et al. (1999), os autores observaram que a autoclavagem da farinha de soja durante um período de $120 \mathrm{~min}$ provocou uma mudança significativa na solubilidade da proteína, causando uma redução de $81,89 \%$ na solubilidade da mesma. Logo, o tratamento térmico é um fator preponderante no ISN e no IDP pois a solubilidade proteica varia inversamente com a qualidade da proteína e com a severidade do tratamento térmico. Sendo a solubilidade a propriedade funcional primária na determinação das características gelatinizantes, espumantes e emulsificantes das proteínas (Cândido, 1998).

\section{CONCLUSÕES}

O processo de torra a $150^{\circ} \mathrm{C}$ por $30 \mathrm{~min}$ fez com que a solubilidade proteica atingisse valores abaixo de $10 \%$, devido a severidade do tratamento. As farinhas provenientes da cultivar BRS 267 foram as que apresentaram um maior conteúdo proteico, podendo ser usadas para melhorar o valor nutricional de alimentos de soja. As farinhas da cultivar Vmax exibiram o maior teor de lipídeos, podendo ser utilizadas nas indústrias de extração de óleo, para o fabrico de uma infinidade de produtos alimentares e não alimentares ou em produtos que visam o aumento do conteúdo lipídico. Já na farinha da cultivar BRS 257, foi observada uma composição química com valores intermediários as demais cultivares, mas com vantagem de não necessitar de processamento térmico para a inativação das LOXs.

\section{REFERENCIAS}

A.O.A.C (ASSOCIATION OF OFFICIAL ANALYTICAL CHEMISTS). Official methods of analysis of the Association of Official Analytical Chemists 18. ed. Washington: AOAC, 3000p, 2007.

A.O.C.S (American Oil Chemists' Society) (Champaign, Estados Unidos). Official and tentative methods of the American Oil Chemists Society - método oficial Ba 10-65. 3. ed. Champaign, 1980.

ARNDT, R. E.; HARDY, R. W.; SUGIURA, S. H.; DONG, F. M. Effects of heat treatment and substitution level on palatability and nutritional value of soy defatted flour in feeds for Coho Salmon, Oncorhynchus kisutch. Aquaculture, v. 180 p. 129-145, 1999.

CÂNDIDO, L. M. B. Obtenção de concentrados e hidrolisados protéicos de Tilápia do Nilo (Oreochromus Niloticus): composição, propriedades nutritivas e funcionais. Tese de Doutorado, UNICAMP/FEA, Campinas/SP, p.207, 1998.

CARRÃO-PANIZZI, M.C.; PIPOLO, A.; MANDARINO, J.M.G.; ARANTES, N.E.; BENASSI, V. de T.; ARIAS, C.A.; KASTER, M.; OLIVEIRA, M.F.; TOLEDO, J.F.F.; CARNEIRO, G.; Breeding specialty soybean cultivars for processing and value-added utilization at Embrapa in Brazil. In: WORLD SOYBEAN RESEARCH CONFERENCE, 8. 2009, Beijing. Abstracts for oral presentations and posters...Beijing: The Chinese Academy of Agricultural Sciences, 2009. p.113, 2009.

CARRÃO-PANIZZI, M. C.; BERTAGNOLLI, P. F.; STRIEDER, M. L.; COSTAMILAN, L. M.; MOREIRA, J. U. V. Melhoramento de Soja para Alimentação Humana na Embrapa Trigo - Safra Agrícola 2011/2012. Passo Fundo/RS. Empresa Brasileira de Pesquisa Agropecuária - Embrapa Trigo. ISSN 1516-5582, p. $27-31,2012$. 
CHEN, P.; BUSS, G. R. Breeding soybean for the soyfoods market: specific traits and strategies for selection. In: PROCEEDINS... III World Soybean Research Conference, IV International Soybean Processing and utilization and III Congresso Mundial de Soja. Foz do Iguaçu, Embrapa Soja, p. 830 835, 2004.

CIABOTTI, S.; BARCELLOS, M. F. P.; MANDARINO, J. M. G.; TARONE, A. G. Avaliações químicas e bioquímicas dos grãos, extratos e tofus de soja comum e de soja livre de lipoxigenases. Ciên. Agrotécnica, v. 30, n. 5, p. 920 - 929, 2006.

CIABOTTI, S.; BARCElOS, M. F. P.; PINHEIRO, A. C. M.; ClEMENTE, P. R.; LIMA, M. A. C. Características sensoriais e físicas de extratos e tofus de soja comum processada termicamente e livre de lipoxigenase. Ciên. Tecnol. Alimentos, v. 27, n. 3, p. 643-648, 2007.

DANTAS, M. I. S.; SILVA, M. G.; PINTO, C. R. R.; PEREIRA, C. A. S. P.; MINIM, V. P. R.; BITTENCOURT, M. C. B. Farinhas de soja sem lipoxigenase agregam valor sensorial em bolos. Rev. Ceres, Viçosa, v. 57, n.2, p. 141-144, 2010.

FRANÇA NETO, J. B.; KRZYZANOWSKI, F. C.; PÁDUA, G. P.; COSTA, N. P.; HENNING, A. A. Tecnologia da produção de semente de soja de alta qualidade - Série Sementes. Circular Técnica no 40, Londrina/PR, ISSN 1516-7860, março, 2007.

GUARIENTI, E. P.; PINHEIRO, E.; GODOY, L. P.; EVANGELISTA, M. L. S.; LOVATO, A. Perdas de matéria-prima: um estudo de caso na indústria de óleo de soja. Engevista, v. 14, n. 1. p. 58-73, abril 2012.

HE, F. J,; CHEN, J. Q.; Consumption of soybean, soy foods, soy isoflavones and breast cancer incidence: Differences between Chinese women and women in Western countries and possible mechanisms. F. Sci. Human Wellness, v. 2, p.146-161, 2013.

NASCIMENTO, M. R. F. Uso de Farinhas de Trigo e Soja (80:20) Pré-cozidas por Extrusão para "Requeijão Cremoso Contendo Trigo-Soja" e Donut. 2008. 83 f. Dissertação. (Mestrado em Ciência e Tecnologia em Alimentos) - Programa de Pós-Graduação em Ciência e Tecnologia de Alimentos, Universidade Federal Rural do Rio de Janeiro, Seropédica, RJ, 2008.

SAIDU, J. E. P. Development, evaluation and characterization of protein, isoflavone enriched soymilk. Louisiana: Faculty of the Louisiana State University. 216 p. (tese de doutorado), 2005.

SANTOS, H. M. C.; OLIVEIRA, M. A.; OLIVEIRA, A. F.; MANDARINO, J. M. G.; CARRÃOPANIZZI, M. C.; LEITE, R. S.; OLIVEIRA, G. B. A.; MOREIRA, A. A.; SILVA, C. E. Desenvolvimento e caracterização físico-química de biscoitos com farinha de soja orgânica de cultivares especiais para a alimentação humana. In: V Jornada Acadêmica da Embrapa Soja. Documentos, 323, p. 79-82, 2012.

SILVA, C. O.; ANDRADE, G. F.; DANTAS, M. I. S.; COSTA, N. M. B.; PELUZIO, M. C. G.; FONTES, E. A. F.; MARTINO, H. S. D. Influência do processamento na qualidade protéica de novos cultivares de soja destinados à alimentação humana. Rev. Nutrição, Campinas, v. 23, n. 3, p. 389-397, 2010.

SILVA, J. B. Características de cultivares de soja convencionais e para consumo humano: análises físicas, químicas e sensoriais (sentidos humano e sensores eletrônicos). Tese de Doutorado (Doutorado em Ciência de Alimentos) - Universidade Estadual de Londrina. Londrina/PR, 2009.

SILVA, M. H. L. Desenvolvimento e caracterização de um isolado protéico de soja modificado com perfil de solubilidade da caseína do leite humano. 96 - 105 f. Tese (doutorado) - Universidade Ferderal de Viçosa. Curso de Pós-Graduação em Ciências e Tecnologia de Alimentos. Viçosa, 2007.

SILVA, S. O.; OLIVEIRA, E. F.; OLIVEIRA, G. B. A.; SILVA, J. B.; CAMPOS-FILHO, P. J.; MANDARINO, J. M. G.; CARRÃO-PANIZZI, M. C. Composição centesimal e solubilidade da proteína de cultivares de soja especiais para alimentação humana no processamento de extrato solúvel de soja. In: III Jornada Acadêmica da Embrapa Soja. Embrapa Soja. Documentos, 297, p. 134-139, 2008. 